Opinion

\section{The human being....}

\section{Opinion}

The human being is a body-soul composite. A human is a matterspirit unity. That it has spirit is incontrovertible-subhuman animals do not have spirit-they do not even celebrate birthdays much less anything else above living basic animal nature on the planet. Give an animal a mirror and one has to lie to oneself to claim any hint of self-awareness or conscious of consciousness demonstrated by the animal. Sub-human animals live by biochemical control. To claim that humans are likewise so limited is to deny rational thinking and free will. Humans can choose, even to thwart their own biological biochemical controls. The human soul allows that by soul spirituality which gives a freedom from matter, ranging from celebrations to basic mathematics to the Ninth Symphony of Beethoven.

This super-nature component (soul-based spirit) means the human body is made for Transcendence-for Matter, Identity, Truth, Oneness, Good, Beauty, and Being itself. The body should be, thusly, used as best as one can for Love which is the projection of the Transcendentals for others. The body should be used spiritually if used consistent with its created and creative potential. That means in synchrony with proper function of all parts of the body as defined in Nature and psycho-socially in synchrony with Transcendence.

The human being is from the Big Bang of creation; is able to choose ever since the Big Bust of Adam and Eve-to choose even wrongly, otherwise "freedom" is meaningless. And the human being is able to choose to follow the Big Bailout of Jesus by living His Mantra of Life, Sacrifice, Virtue, Love, Humanity, Peace, Freedom, and Death without Fear-most easily done by Sacramental Life and reliving the "Last Words of Jesus on the Cross". For humans, Spirituality reigns and means that "There is more!" including that "the dead are not dead" because one will rejoin, when the Big End finally comes,
Volume 6 Issue 6 - 2017

\section{Samuel A Nigro M.D}

Retired, Assistant Clinical Professor Psychiatry, Case Western Reserve University School of Medicine, USA

Correspondence: Dr. Samuel A Nigro M.D., Retired,Assistant Clinical Professor Psychiatry, Case Western Reserve University School of Medicine, 2517 Guilford Road, Cleveland Heights, Ohio 44II8, USA, Tel 216 932-0575, Email sam@docnigro.com

Received: May 01, 2016 | Published: February 06, 2017

what was before the Big Bang pre-Universe. There is a Statimuum (a scientifically based timeless immediate compression of all) pre-Big Bang pre-Universe which all will rejoin at the Big End. No doubt, if "justice" and spirit mean anything at all, each human will receive the Heavenly gifts of all Transcendence performed and/or the hell-fire torture of all evil performed. Humans will get back what they are...so, as the ancients said: "Do the Transcendent and avoid evil."

\section{Acknowledgments}

None.

\section{Conflicts of interest}

None.

\section{Funding}

None. 